Even if Prof. Carpenter were proved to be right, however, and these "mimicking" resemblances really did function in the way he supposes, "natural selection" would be incompetent to explain them. "Natural selection" in a sense is a truism; it merely asserts that an organism exists and maintains itself, which is sufficiently obvious. But what the theory covertly assumes is that random inheritable variations in all directions are constantly taking place by chance-and that is simply not true. All the experimental evidence obtained by testing this point has given the same answer, and it is surely unsafe to base any biological theory on an assumption which has proved to be false. But it may be answered that 'mutations' are inheritable. Mutations have now been artificially produced, and always by similar experiments. If the eggs or young embryos are exposed to noxious conditions, then a large number are killed; some survive and develop normally whilst there is a border group of what we may term the 'half-killed' which develop into mutations. All mutants compared with the type are defective in vigour and viability. Mohr, the great authority on Drosophila, has constructed a scale of mutations : the slight mutations produce a slight effect on viability, the more obvious ones a greater effect, the most obvious a semi-lethal effect. Moreover, if mutants can be restored to normal conditions, after a certain number of generations they revert to normal development, and the mutant appearance which Johannsen defined as a "superficial disturbance of the chromosomes" passes off. No mutation has ever given rise to a natural race.

We have definite evidence that insects, like other animals, react to changes in the environment by changes in growth and appearance, and that when these changes in the environment are long continued, their effects become so engrained in the constitution that they are in ever-increasing measure inherited by the offspring. This has been proved by Heslop Harrison for the egg-laying habits of Pontania salicis, by Durkheim for the coloration of Pierid pupæ, for feeding habits by Miss Sladden and, mirabile dicta, for the colour of the imago of butterflies by Weismann himself.

When fully documented evidence for evolution as displayed by a minute study of species and races of living forms or by the study of lineage series in fossils is carefully studied, this dependence of evolutionary change on change in habit and function becomes apparent. It is useless to demand miracles in the shape of supposedly beneficial mutations to explain changes where the full evidence is not at hand. When and if it is available, I am convinced that apparently inexplicable cases will yield to the same explanation of inherited habit as those cited above.

\section{West Bank,}

$$
\text { E. W. MacBride. }
$$

$$
\text { Alton, }
$$

Hampshire.

\section{The External Forces Acting on Chromosomes}

According to Darlington ${ }^{1}$, in somatic mitosis or meiosis, "the equilibrium position reached at metaphase may . . . be described as the result of the combination of three kinds of repulsion acting on bodies in the confined space of the spindle", the repulsions being between chromosomes, between spindle attachments, and between poles and spindle attachments. If therefore at the first metaphase of meiosis there should exist two kinds of bivalents the different shapes or sizes of which cause the spindle attachments of the component chromosomes to be farther apart in one kind than in the other, we should expect the former type of bivalent to be pushed to the edge of the plate.

In the plant Silene Otites Wibel, the chiasmata at first metaphase are all terminal or nearly so, and a mixture of rod bivalents with one chiasma and ring bivalents with two chiasmata is found, the spindle attachments being farther apart in the rod bivalents. The latter tend regularly to be arranged on the edge of the plate, a minor, but none the less striking, verification of the theory.
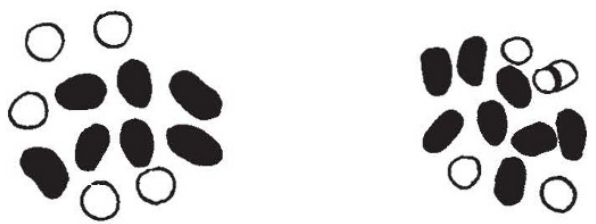

Fig. 1. Twn polar views of the first metaphase of meiosis in pollen mother cells of Silene Otites Wibel. For the purpose of illustration the bivalents with one chiasma are shown in outline. ( $\times 3000$ approx.).

In the polar views represented in Fig. 1 the bivalents with one chiasma can be distinguished by their smaller and more circular cross-section. The illustrations represent an apparent contradiction of the general rule that the largest chromosomes are found on the outside of the metaphase plate, but actually, as can be seen more clearly in side views, the difference is one of shape rather than of size.

School of Agriculture,

JAMES L. FyFE.

Cambridge. July 16.

${ }^{1}$ C. D. Darlington, "Recent Advances in Cytology". J. \& A Churchill, London, 1932.

THE different distribution of rod and ring bivalents found by Mr. Fyfe in Silene is a clear and hitherto unnoticed example of the principle of repulsionequilibrium in the formation of the metaphase plate. This effect evidently depends on the numbers of chromosomes, on the equality of their sizes combined with the variation in the number of their chiasmata, and on a certain size-relationship of chromosomes and spindle. Less conclusive evidence of the same distribution is to be found in my figures of Primula sinensis ${ }^{1}$, Campanula persicifolia and diploid Tradescantia. In the last case the body-repulsions assist in producing the differential effect. Where the chromosomes are more numerous, as in Aesculus ${ }^{2}$, the differential distribution is not clear without statistical treatment.

The detailed study of the congression and distribution of the bivalents on the plate in relation to their size and chiasma structure makes it possible now to describe the forces at work with more precision than a few years ago, especially in showing that the repulsions are an inverse function of distance ${ }^{3}$.

\section{D. Darlington.}

John Innes Horticultural Institution, London, S.W.19.

\footnotetext{
1 . Genetics, 24, 65 (1931).

2 Upcott, $J$. Genetics; in the press.

${ }^{3}$ MS. in the custody of the Royal Society (1935).
} 